\title{
Health Education - A Chronic Disease Study
}

\author{
Isilda Rodrigues ${ }^{1}$, Clara Costa Oliveira ${ }^{2}$
}

${ }^{1}$ University of Trás-os-Montes and Alto Douro, UTAD, Department of Education and Psychology, CIIE - University of Porto, SPCE; Quinta de Prados, Apartado 1013, 5001-801, Vila Real, Portugal

${ }^{2}$ University of Minho: CEHUM; Institute of Education; SPCE; STOL; NEIP isilda@utad.pt,claracol@ie.uminho.pt

\begin{abstract}
This project on Health Education is directed to chronic diseases and it is extremely accurate, since these pathologies represent, nowadays, one of the leading causes of mortality. The central goals of this research are:

a) To educate health caregivers (formal, non-formal and informal) on chronic patients and diseases;

b) To promote health education for children, youth and adults in the context of Lifelong Learning.

We used qualitative methods, using for data collection 18 questionnaires related to chronic diseases. The study sample was deliberate, and consists of about 700 students from various undergraduate and masters of a University of North Portugal

We think that the knowledge produced in developing this research is doubly important. Firstly, because it is a truly unprecedented one, which may contribute to increase the overall knowledge of some chronic diseases. And secondly, because we think that with this work, we contribute to the improvement of the training of children, young people and adults involved in the project and thereby enhance them in the near future, improving the quality of life of patients with chronic diseases.
\end{abstract}

Keywords: Health education; prevention; rehabilitation; chronic diseases

\section{INTRODUCTION}

The present paper and the project from which it derives are within the scope of Health Education, understanding this concept as defined by Oliveira \& Gonçalves:

"[...] Health education means contributing to people's autonomy to identify and to use the ways and means to preserve and improve their lives. Considering that health education is related to learning, designed to achieve health, it is necessary that it be oriented towards serving the population according to their reality. Thus health education must provoke conflict in individuals, creating an opportunity for people to think and rethink their culture, and to transform their reality "(Oliveira and Gonçalves, 2004, p. 761

In this context, chronic diseases are of crucial importance since they are currently the leading cause of mortality and morbidity with significant economical implications. The Fourth International Conference on Health Promotion in Jakarta, under the motto 'Health Promotion in the 21st Century' (WHO, 1997), gave us directives that reinforced the importance of working with chronic diseases in different contexts. According to Feio and Oliveira (2015):

"The strategies implemented until the date of its implementation were evaluated, the determinants of health were redefined (with emphasis on aging, population with chronic diseases and the emergence of new diseases), health promotion as an indispensable element for its development, which has to respond to the new determinants identified, and it was also questioned the importance of the private sector in health promotion "(Feio and Oliveira, 2015, p.706).

According to the World Health Organization a chronic disease is defined as being permanent, producing incapacity, residual deficiencies and being caused by irreversible pathological alterations, which may require long periods of supervision, observation and /or care (DGS, s/d), and self-care, we add. Chronic diseases have some common characteristics, of which we highlight: (1) they require 
complex long-term responses with inter-multi-transdisciplinary intervention by health care providers; (2) they require a caregivers' role and functions redefinition, including the recognition of non-formal caregivers; (3) they imply the implication of patients, promoting salutogenesis (Antonovski, 1993) and empowerment, towards their autonomies. "Our review of educational institutions leads to revise the image we have of humankind. The creatures needed by schools as clients do not have the autonomy or the motivation to develop on their own "(Illich, 1985, p.114).

The (formal, non-formal and informal) health educator has an important role in encouraging the production of these steps in the chronic patient. The health educator can not therefore position himself as a dominat and self-sufficient instructor (Freire, 1970) towards chronic patients; It is incumbent upon him to encourage their psychological and social empowerment (Kleba and Wendausen, 2009), so that the patient can be the author of his life history, although living in suffering.

However, we must always bear in mind that, for ethical reasons, empowerment can never be used as an argument for the lack of accountability of health care providers, nor for blaming the victim (Rodrigues and Santos, 2001). One of the major challenges in the development of this project has been the level of existing beliefs in the training of some education and health professionals. Thus, from the epistemological point of view, it is important to analyze and discuss the evolution of the knowledge of these diseases, as well as their myths and beliefs (Oliveira and Gonçalves, 2004).

We therefore consider it extremely opportune to work on these issues at the level of initial teacher training, as they will contribute to the training of children and young people and thus, in the near future, improve the well-being of patients with chronic diseases. The knowledge of the past of chronic diseases is indispensable to understand its evolution and its prevalence today. This survey is fundamental for two essential reasons, on the one hand, because it allows to increase the knowledge about the historical evolution of some chronic diseases and, on the other, because it can promote a better understanding of the scientific concepts, on the same diseases. Both aspects are relevant in the training of health care providers, namely teachers, as in this case.

\section{Methodology}

In this investigation we used essentially a qualitative-descriptive methodology. The study was developed at the Curricular Unit (UC) of History of Science belonging to the Master's Degree Program in Teaching (Teacher's Training) of a Portuguese university. The present research was developed under the motto of the importance of chronic diseases' knowledge to the training of these students, future health educators.

The 54 students, divided into groups of 3, enrolled in the UC of History of Science, collected, in the academic year of 2013/2014, data referring to 700 students, of various degrees and masters, from the same university. To facilitate access to the data we opted for a non-probabilistic sample of convenience. The data collection took place in different classrooms where the students were having classes. Authorization was previously requested. We used 18 self-completion questionnaires, built with the collaboration of the students involved in the study, with a set of questions to test participants' knowledge about the subjects under study. All the questionnaires presented the same structure, being, however, all different. They had two sections, one common, concerning the general issues of chronic diseases and the other concerning a specific chronic disease. All the questionnaires used were previously validated by 2 specialists, one from the area of Health Education and another from the Didactics area; later they had been validated by students with similar characteristics of those of the sample (but were not involved in the research).

\section{RESUlts AND DiscusSion}

In this section we present, in the form of tables and graphs, some of the results obtained in this study. The data for the first two questions included the sample as a whole, that is, $\mathrm{N}=700$. The sample number for the other chronic diseases was 40 students for each one.

In terms of students' perception of the concept of chronic disease (Table 1), two categories of response were found: "it is a long-term disease" (55\%) and "it is a disease that has no cure" (45\%), 12\% did not respond. 
Table1. Students' Perception on Specific Chronic Diseases

$\mathrm{N}=700$

\begin{tabular}{|l|c|}
\hline \multicolumn{1}{|c|}{$\%$} & $\%$ \\
\hline Categories of answer & $55 \%$ \\
\hline $\begin{array}{l}\text { It is a long term disease } \\
\text { No disease with no cure }\end{array}$ & $45 \%$ \\
\hline & $12 \%$ \\
\hline
\end{tabular}

We found that most of the students in the sample had difficulty in defining what a chronic disease is. As we have already mentioned, chronic diseases are diseases with prolonged clinical manifestations that affect people's quality of life. These results show something worrisome, that these subjects are not discussed and / or worked in Higher Education. We are of the opinion that the greater the discussion and reflection on chronic diseases, the greater its prevention and the gains in health and quality of life in the future.

As for the identification of diseases considered chronic, the issue included a listing of 21 diseases and students were asked to indicate chronic diseases. Most respondents did not identify them correctly (Figure 1).

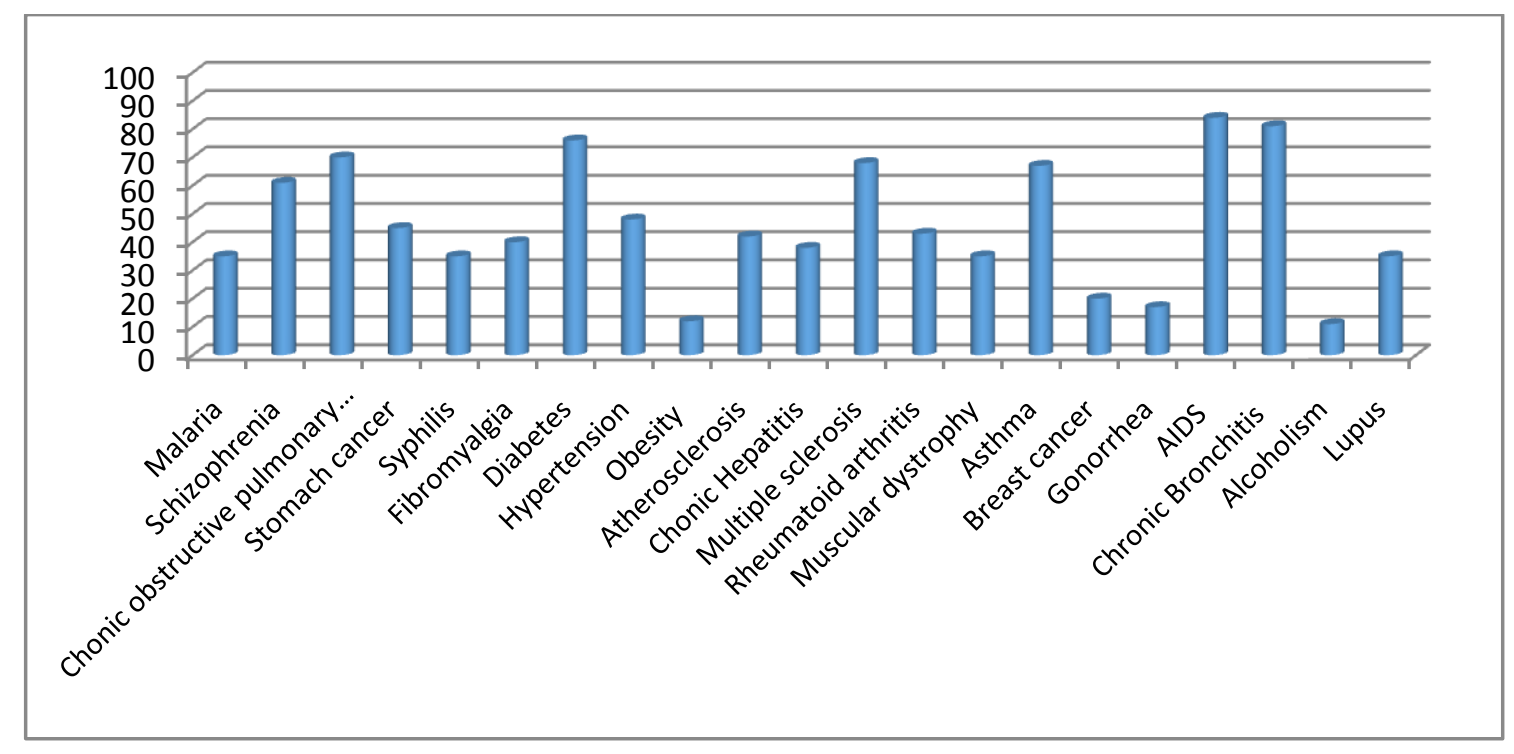

Fig1. Students' Perception on Specific Chronic Diseases

We found that many of the chronic diseases were not identified by the majority of the students, but other diseases that were not chronic diseases were noted. Correctly identified by most respondents were AIDS (81\%), Chronic Bronchitis (79\%), Diabetes (75\%) and Asthma (66\%). These diseases are the most known and present great incidence in the population. The remaining chronic diseases, either because they are less well known or because they have a lower incidence in the Portuguese population, were not identified. See, for example, Lupus (32\%) and Fibromyalgia (38\%). However, were characterized as chronic diseases Gonorrhea (15\%), Obesity (10\%), Syphilis (32\%), among others. Regarding the knowledge about the different chronic diseases, most students answered incorrectly to the questions related to etiological agent, forms of transmission, control of the chronic disease and data on its historical evolution.

Let's put it in a concrete way, with some results for Diabetes, Chronic Hepatitis, AIDS, Alcoholism and Lupus. Regarding the definition of Diabetes, the response categories found were: high blood sugar levels (40\%) and anomalies in insulin production (35\%). These responses proved to be quite incomplete, since the cause or organ responsible for the disease was not identified, but only some of its manifestations were mentioned. It should be noted that $25 \%$ of the students did not respond to this question, which, in our opinion, reveals a great lack of knowledge about the disease. This is reinforced in the remaining questions regarding historical data about the disease and its evolution, as well as how to act in crisis situations. The vast majority have revealed that they do not know the basic procedures to take in situations of hypoglycemia. 
Regarding Chronic Hepatitis, only 50\% of the students report that the transmission of this disease is done through a virus. We have observed, in diseases in general, that most of the students have great difficulty in identifying the causal agent. They confuse viruses with bacteria and fung. We also verified, with regard to ways of contagion, that only $20 \%$ considered that Chronic Hepatitis can be transmitted through pregnancy and childbirth. No one considered that transmission could occur in the dentist, manicure, acupuncture and tattoos. We know nowadays that these spaces are susceptible of transmitting the disease, because some of the material used in these places is not properly sterilized.

About AIDS, which is one of the most known chronic diseases, the data obtained show that $56 \%$ of the students still considered those who have HIV to have AIDS. Only 32\% report that this disease was discovered in the 20 th century and $72 \%$ pointed to the African continent as the place where the disease first appeared.

In relation to alcoholism, only about $9 \%$ of the students identified this pathology as a chronic disease. Regarding the questions concerning the veracity, or not, of some historical data on alcoholism, we have noticed that the majority manifest little knowledge. Indeed, some of the true statements were considered false and vice versa. For example, $22.4 \%$ considered the statement "Hippocrates (385 BC) to have falsified the use of alcohol as contributing to the development of several other diseases," which is true; The third assertion "In Europe and the United States alcohol consumption declines after the Industrial Revolution" is false and 20.4\% answered that this was true. The last statement "In 1990, Edwards and Gross proposed the concept of "Alcohol Dependence Syndrome "is also false, but 79.6\% considered it to be true. Analyzing the answers given, we conclude that most students ignore the historical evolution of knowledge about this chronic disease. With regard to the question that they intended to indicate from a given list of diseases, those that in their opinion may be provoked by the abusive intake of alcohol, the most frequent diseases mentioned were: Cirrhosis with $85.71 \%$, Myocardial attack with 44, 9\% and Gastritis with $36.73 \%$. After analyzing the answers, we believe that most of the students inquired do not recognize that there are several health consequences caused by abusive alcohol intake.

Lack of knowledge about most chronic diseases is reinforced when we look at Lupus results. We found, through data analysis, that a large percentage (68\%) of students in the sample are unaware of the disease. Regarding the question about the respective treatment, we found that the lack of knowledge is significant; $39 \%$ of students reported the wrong answer and $27 \%$ did not respond. Regarding the prevention of the disease, we found that the most indicated response options were healthy eating (53\%), avoiding sun exposure (47\%) and with equal percentage complying with the medical prescription. However, all of the response categories mentioned in the question are ways of preventing the disease and they were not assigned (figure 2)

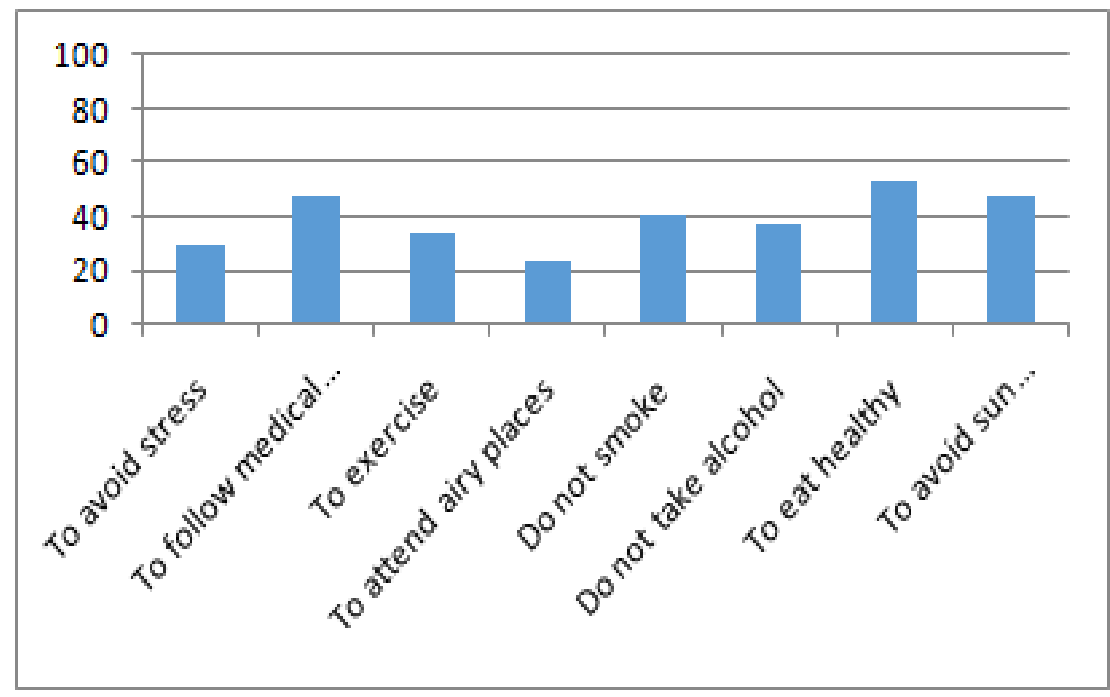

Fig2. Students' Perception on ways of preventing Lupus

On the correspondence between some historical facts related to disease lupus and its authors data are shown in fig. 3 . 


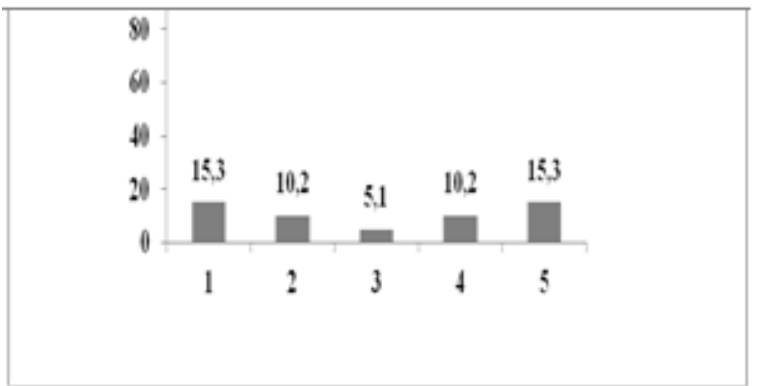

Fig3. Students' perception on the history of Lupus

1 - Observed persons with injuries in the hair and associated these lesions with wolf bites - Pierre Lazenave;

2 - Characterized in detail the involvement of various organs in the symptoms of the disease - Ser William Osler;

3 - Added the word "systemic" to the designation of the disease - Being William Osler;

4 - Created general criteria to define Lupus clinical classification-American College of Rheumatology

5 - Added new classifying criteria for Lupus - Systemic Lupus International Collaborating Clinics

We found that most of the answers regarding the correspondences between historical Lupus data and their authors were wrong. The students reveal a great lack of knowledge about this disease. We believe that this lack of knowledge can partly result from the non-inclusion of these themes in school curricula.

\section{Final CONSIDERATIONS}

These data suggest that the participants of the study sample showed reduced knowledge about the mentioned chronic diseases. Indeed, most of the students in the sample had difficulty defining what is a chronic disease; - the most common chronic diseases were: Diabetes, AIDS, Chronic Bronchitis and Asthma; - most students mistakenly pointed out some diseases as being chronic diseases and many diseases that are chronic were not considered; - there is a great lack of knowledge about the various chronic diseases analyzed, both in terms of knowledge evolution and in terms of responsible agent, transmission and primary/secondary preventions.

The health of all is now clearly seen in every society as a fundamental right of the person. WHO emphasized in its 1998 annual report that well-being and health are closely related. In this sense, the experts consider that health education should be oriented towards the preservation of individual and collective health. We are, therefore, at the primary and secondary levels of health education. This is also one of the concerns of the Portuguese Ministry of Education, considering that "educating for health is about giving children and young people knowledge, attitudes and values that help them to make choices and to make decisions that are appropriate to their health" (MEC, 2013). For example: In 2010, the prevalence of diabetes in Portugal reached $12.4 \%$ of the population between the ages of 20 and 79 (991000 individuals). [...]. In 2013 it roused to $13.0 \%$, that is, more than one million individuals between the ages of 20 and 79 have diabetes [...]. It plays an important role in death's causes and in 2012 there were the highest number of deaths due to diabetes since there are computerized mortality records in the INE [Portuguese Official Statistic Numbers] (Cortes, 2015).

According to the policies advocated, this research team understands that one of the strategies to be adopted to reduce the number of patients with chronic diseases is to encourage the involvement of health and education professionals in the prevention of these diseases, thus investing in Education in Health at primary and secondary levels. We believe that educational professionals have a decisive influence on their educational actions. As for health professionals, they are the most visible face of public health infrastructures. Therefore, both groups must possess (in) formation in quantity and quality, precious in this area. In light of the above, we believe that the development of this project could contribute to increase knowledge about chronic diseases (Branco, Nogueira, Contreiras, 2005), to improve the training of Health and Education future professionals and, consequently, to ameliorate the well-being of their chronically ill students and/or patients.

Notice: The persons mentioned as authors collaborated fairly in the preparation of the text of the article. The data collection was done in the Curricular Unit of History of Science of the responsibility of one of the authors.

Translation of quotes from Portuguese to English were done by the authors of this paper. 


\section{REFERENCES}

ANTONOVSKY, Aaron. (1993). Complexity, Conflit, Chaos, Coherence, Coercion and Civility. Social Science \& Medicine, 37(8):969-74.

BRANCO, MJ.; NOGUEIRA, P \& CONTREIRAS, T. Uma observação sobre a prevalência de algumas doenças crónicas em Portugal Continental (Relatório), Lisboa: Ministério da Saúde /Instituto Ricardo Jorge, 2005. Disponível em http://repositorio.insa.pt/bitstream/ 10400.18/ 285/1/Relatório\%20prevalência\%20doenças\%20crónicas.pdf [consultado em 20 de março de 2015].

CASSELL, E. The nature of suffering and the goals of medicine. Oxford: Oxford University Press, 2004.

CORTES, A. Breve olhar sobre o estado da saúde em Portugal. Sociologia, problemas e práticas, n. 80, p. 117-143, 2015.

DGS - DIREÇÃO GERAL DE SAÚDE. Definição de doença crónica. http://pns.dgs.pt/files/ 2010/09/ddc.pdf [consultado em 20 de março de 2015]

FEIO, A.; OLIVEIRA, C. Confluências e divergências conceituais em Educação em Saúde. Revista Saúde e Sociedade (Brasil), nº 24, p.703-715, 2015.

FREIRE, P. Pedagogia do Oprimido. Rio de Janeiro: Paz e Terra, 1970.

ILLICH, I. Sociedade sem escolas. S. Paulo: Vozes, 1985.

KLEBA, M. E.; WENDAUSEN, A. Empoderamento: processo de fortalecimento dos sujeitos nos espaços de participação social e democratização política. Saúde Soc. São Paulo, v.18, n.4, p. 733743, 2009.

MEC - MINISTÉRIO DE EDUCAÇÃO E CULTURA. Promoção e Educação Para a Saúde. 2013 [disponível em: http://www.dgidc.minedu.pt/educacaosaude/index.php?s=directorio\&pid=36 consultado em 26/05/2013].

OLIVEIRA, H. M. \& GONÇALVES, M. J. Educação em saúde: Uma experiência transformadora. Revista Brasileira de Enfermagem, 57 (6), p. 761-763, 2004.

RODRIGUES, C. H.; SANTOS, E. F. Empowerment: Ciclo de Implementação, Dimensões e Tipologia. Gestão \& Produção. v.8, n.3, p.237-249, 2001.

SILVESTRE, C. Educação e formação de adultos e idosos - Uma nova oportunidade. $3^{\text {a }}$ Ed. Lisboa: Instituto Piaget, 2013. 